\title{
Association of Metabolic Syndrome Components and Overactive Bladder in Women
}

Corc Baytaroglu ${ }^{1}$, Emrah Sevgili ${ }^{1}$

1. Cardiology, Avcılar Hospital, Istanbul, TUR

Corresponding author: Emrah Sevgili, emrahsevgilicardio@gmail.com

\section{Abstract \\ Background}

To identify associations between metabolic syndrome (MS) components and overactive bladder (OAB) in women.

\section{Methodology}

The present study was conducted prospectively between February 2021 and April 2021 and included the assessment of women admitted to the cardiology outpatient clinic and their female relatives. Records were made of the demographic characteristics of patients and blood tests, including cholesterol, high-density lipoproteins (HDL), low-density lipoproteins (LDL), triglyceride, and fasting glucose levels (FG). In addition, the score on the Overactive Bladder Questionnaire-8-item (OAB-V8) form was noted. The study population was divided into two groups according to OAB-V8 score. The groups were compared in terms of participant demographic properties, OAB-V8 scores, metabolic component values, and blood test results.

\section{Results}

In total, 200 participants with a mean age of 49.8 years were enrolled in the study. Participants with OAB had significantly higher body mass index (BMI) $\left(30.1 \mathrm{~kg} / \mathrm{m}^{2}\right.$ versus $\left.27.1 \mathrm{~kg} / \mathrm{m}^{2} ; \mathrm{p}=0.001\right)$ and longer waist circumference $(97.8 \mathrm{~cm}$ versus $89.0 \mathrm{~cm} ; \mathrm{p}=0.001)$. Similarly, the mean FG and LDL levels were significantly higher in participants with $\mathrm{OAB}(\mathrm{p}=0.001$ and $\mathrm{p}=0.001$ ). Lastly, mean OAB-V8 score was 20.2 for participants with $\mathrm{OAB}$ and 4.8 for participants without $\mathrm{OAB}$. Multivariate regression analysis showed that higher BMI and longer waist circumference were significantly associated with OAB (1.228-fold; $p=0.001$ and 1.058 -fold; $\mathrm{p}=0.001$, respectively). Additionally, multivariate regression analysis found that higher LDL level and FG were predictive factors for $\mathrm{OAB}$ (1.115-fold; $\mathrm{p}=0.003$ and 1.229 -fold; $\mathrm{p}=0.001$, respectively).

\section{Conclusions}

The present study found that higher BMI, longer waist circumference, and higher LDL and FG levels were predictive factors for $\mathrm{OAB}$ development in women.

Review began 04/14/2021 Review ended 04/24/2021 Published 04/30/2021

๑) Copyright 2021

Baytaroglu et al. This is an open access article distributed under the terms of the Creative Commons Attribution License CC-BY 4.0., which permits unrestricted use, distribution, and reproduction in any medium, provided the original author and source are credited.
Categories: Cardiology, Endocrinology/Diabetes/Metabolism, Urology

Keywords: bmi, glucose, metabolic syndrome, overactive bladder, waist circumference

\section{Introduction}

Overactive bladder $(\mathrm{OAB})$ is characterized by voiding urgency, frequency, and nocturia, with or without urinary incontinence, in the absence of pathologies that can cause these symptoms [1]. Although OAB is not a life-threatening disease, it is associated with deterioration of quality of life, social isolation, and cost to the healthcare system [2]. The true incidence of OAB is still unknown, and previous studies have reported $\mathrm{OAB}$ incidence in a wide range [3]. Moreover, the pathophysiology of OAB is not well understood, and morphologic changes in detrusor muscle, neuroplasticity, inflammation, and pelvic ischemia are believed to be among the underlying factors [4]. Recently, many studies have investigated the correlation between OAB and other diseases, including glucose intolerance, hypertension, nervous system diseases, and metabolic syndrome (MS) $[5,6]$.

MS was first described in the late 90s to define cardiovascular risk factors, including dyslipidemia, hypertension, insulin resistance, and obesity. As a result of reduced physical activity and changing dietary habits, MS has become a pandemic disease all around the world [7]. Aguilar et al. reported that one-third of Americans meet the criteria for MS [8]. In another study, Sigit et al. stated that $28 \%$ of men and $46 \%$ of women were affected by MS in Indonesia [9]. Due to the effects of MS such as glucose intolerance and pelvic ischemia, its relationship with urological diseases is under close observation.

Although previous studies discussed the connection between MS and OAB, there is no consensus on the effect of MS components on OAB. Additionally, studies investigating the relationship between MS 
components and $\mathrm{OAB}$ in women are limited. In the present study, we aimed to identify associations between MS components and $\mathrm{OAB}$ in women.

\section{Materials And Methods}

The present study was conducted prospectively between February 2021 and April 2021 and included the assessment of women admitted to the cardiology outpatient clinic and their female relatives. All participants signed informed consent forms for enrollment in the study, and the study was planned in accordance with the Helsinki Declaration. To diagnose OAB, all participants completed the Overactive Bladder Questionnaire-8-item (OAB-V8) form (validated Turkish version). Exclusion criteria included the inability to complete the OAB-V8 form, presence of diseases which may be associated with OAB (neurologic disorders, psychiatric illnesses, urinary system malignancies, gynecologic cancers), and being < 18 years old. Additionally, patients with active urinary system infection and those with a history of pelvic surgery and pelvic radiation were excluded from the study.

Records were made of the demographic characteristics of patients, including age (age), body mass index (BMI) $\left(\mathrm{kg} / \mathrm{m}^{2}\right)$, smoking status, waist circumference $(\mathrm{cm})$, presence of constipation, history of hysterectomy and hypertension, and menopause status. Additionally, blood tests including cholesterol, high-density lipoproteins (HDL), low-density lipoproteins (LDL), triglyceride, and fasting glucose (FG) levels were conducted. In addition, the score on OAB-V8 form was noted.

\section{Metabolic syndrome criteria}

The presence of MS is proven if three or more of the following five criteria are met: waist circumference over 35 inches for women, blood pressure higher than 130/85 mmHg, fasting triglyceride level higher than $150 \mathrm{mg} / \mathrm{dL}$, fasting HDL level less than $50 \mathrm{mg} / \mathrm{dL}$ for women, and FG level over $100 \mathrm{mg} / \mathrm{dL}$.

\section{Overactive Bladder Questionnaire-8-item}

The OAB-V8 form includes eight questions to define the presence and severity of OAB symptoms, including urgency, frequency, nocturia, and urgency urinary incontinence. Patients answer questions on their own and the total OAB-V8 score is calculated by adding the scores for all answers. OAB-V8 scores 8 or higher indicate the presence of $\mathrm{OAB}$ and $\mathrm{OAB}-\mathrm{V} 8$ scores less than 8 indicate the absence of $\mathrm{OAB}$.

The study population was divided into two groups according to the OAB-V8 score. Participants with OAB-V8 score $\geqslant 8$ were categorized as group 1 and those with OAB-V8 score were $<8$ classified as group 2 . The groups were compared in terms of demographic properties, OAB-V8 scores, metabolic component parameters, and blood test results.

\section{Statistical analysis}

Statistical analysis was performed using SPSS version 25 (IBM Corp., Armonk, NY, USA). Normality of distribution of the variables was evaluated using Shapiro-Wilk test and Q-Q plots. The Student's t-test was chosen for comparison of the normally distributed variables, and non-normally distributed values were evaluated using the Mann-Whitney U test. Quantitative data were expressed as mean \pm standard deviation values. Categorical variables were classified and analyzed using the Chi-square test or Fisher's exact test. Binary logistic regression analysis was chosen to evaluate risk factors for the presence of $\mathrm{OAB}$. The data were analyzed at $95 \%$ confidence level, and p values of less than 0.05 were accepted as statistically significant.

\section{Results}

At the end of the evaluation, 200 participants with a mean age of $49.8 \pm 9.1$ years were enrolled in the study. The mean BMI was $28.0 \pm 4.3 \mathrm{~kg} / \mathrm{m}^{2}$, and $31.5 \%$ of the study participants were smokers. The mean HDL, LDL, and triglyceride levels were $50.0 \pm 4.4 \mathrm{mg} / \mathrm{dL}, 115.1 \pm 15.5 \mathrm{mg} / \mathrm{mL}$, and $153.3 \pm 26.1 \mathrm{mg} / \mathrm{dL}$, respectively. Furthermore, the mean FG level was $103.5 \pm 9.5 \mathrm{mg} / \mathrm{dL}$. The mean waist circumference was $91.9 \pm 14.5 \mathrm{~cm}$. In total, 69 (34.5\%) participants had hypertension and 74 (37\%) were post-menopausal. Demographic characteristics and blood test outcomes of participants are summarized in Table 1. 


\section{Cureus}

\begin{tabular}{|c|c|}
\hline & $\mathrm{n}=\mathbf{2 0 0}$ \\
\hline Age (years) ${ }^{\star}$ & $49.8 \pm 9.1$ \\
\hline BMI $\left(\mathrm{kg} / \mathrm{m}^{2}\right)^{\star}$ & $28.0 \pm 4.3$ \\
\hline Smoking status & $63(31.5 \%)$ \\
\hline LDL $(\mathrm{mg} / \mathrm{mL})^{*}$ & $115.1 \pm 15.5$ \\
\hline $\mathrm{HDL}(\mathrm{mg} / \mathrm{dL})^{\star}$ & $50.0 \pm 4.4$ \\
\hline Cholesterol (mg/dL)* & $205.5 \pm 28.7$ \\
\hline Triglyceride $(\mathrm{mg} / \mathrm{dL})^{\star}$ & $153.3 \pm 26.1$ \\
\hline $\mathrm{FG}(\mathrm{mg} / \mathrm{dL})^{\star}$ & $103.5 \pm 9.5$ \\
\hline Waist circumference $(\mathrm{cm})^{\star}$ & $91.9 \pm 14.5$ \\
\hline Constipation & 37 (17.5\%) \\
\hline Hysterectomy & $21(10.5 \%)$ \\
\hline Hypertension & 69 (34.5\%) \\
\hline Post-menopausal status & $74(37.0 \%)$ \\
\hline
\end{tabular}

\section{TABLE 1: Demographic data of all patients.}

*mean \pm standard deviation

BMI: body mass index; HDL: high-density lipoprotein; LDL: low-density lipoprotein; FG: fasting glucose

Comparison of participants with and without OAB revealed that age, smoking status, HDL level, cholesterol level, and triglyceride level were similar between the groups $(p=0.986, p=0.784, p=0.766, p=0.910$, and $p$ $=0.424$, respectively). Moreover, the presence of constipation, hysterectomy history, hypertension rate, and post-menopausal status were comparable between groups $(\mathrm{p}=0.743, \mathrm{p}=0.527, \mathrm{p}=0.980$, and $\mathrm{p}=0.679$,

respectively). However, participants with OAB had significantly higher BMI $\left(30.1 \mathrm{~kg} / \mathrm{m}^{2}\right.$ versus $27.1 \mathrm{~kg} / \mathrm{m}^{2} ; \mathrm{p}$ $=0.001)$ and longer waist circumference $(97.8 \mathrm{~cm}$ versus $89.0 \mathrm{~cm} ; \mathrm{p}=0.001)$. Similarly, the mean FG and LDL levels were significantly higher in participants with $\mathrm{OAB}(\mathrm{p}=0.001$ and $\mathrm{p}=0.007$, respectively). Lastly, mean $\mathrm{OAB}-\mathrm{V} 8$ score was 20.2 for participants with $\mathrm{OAB}$ and 4.8 for participants without $\mathrm{OAB}(\mathrm{p}=0.001)$ (Table 2). 


\section{Cureus}

\begin{tabular}{|c|c|c|c|}
\hline & OAB $(n=64)$ & Non-OAB ( $n=136)$ & P-Value \\
\hline Age (years) & $49.8 \pm 9.1$ & $49.7 \pm 9.2$ & 0.986 \\
\hline BMI (kg/m²) & $30.1 \pm 3.4$ & $27.1 \pm 4.3$ & 0.001 \\
\hline Smoking status & $21(32.8 \%)$ & 41 (30.1\%) & 0.784 \\
\hline LDL (mg/mL) & $119.5 \pm 17.5$ & $113.1 \pm 14.2$ & 0.007 \\
\hline HDL (mg/dL) & $50.2 \pm 4.5$ & $50.6 \pm 4.4$ & 0.766 \\
\hline Cholesterol (mg/dL)* & $205.1 \pm 26.9$ & $205.6 \pm 25.9$ & 0.910 \\
\hline Triglyceride $(\mathrm{mg} / \mathrm{dL})^{\star}$ & $155.2 \pm 27.9$ & $152.0 \pm 25.3$ & 0.424 \\
\hline $\mathrm{FG}(\mathrm{mg} / \mathrm{dL})^{\star}$ & $111.7 \pm 8.2$ & $99.6 \pm 7.3$ & 0.001 \\
\hline Waist circumference $(\mathrm{cm})$ & $97.8 \pm 15.3$ & $89.0 \pm 13.1$ & 0.001 \\
\hline Constipation & $11(17.2 \%)$ & $26(19.1 \%)$ & 0.743 \\
\hline Hysterectomy & 8 (12.5\%) & $13(9.6 \%)$ & 0.527 \\
\hline Hypertension & 22 (34.3\%) & 47 (34.6\%) & 0.980 \\
\hline Post-menopausal status & 25 (39.1\%) & 49 (36.1\%) & 0.679 \\
\hline OAB-V8 score* & $2 \pm 7.3$ & $4.8 \pm 2.1$ & 0.001 \\
\hline
\end{tabular}

TABLE 2: Comparison of demographic data of patients between groups.

*mean \pm standard deviation

BMI: body mass index; HDL: high-density lipoprotein; LDL: low-density lipoprotein; FG: fasting glucose; OAB: overactive bladder; OAB-V8: Overactive Bladder Questionnaire-8-item

Multivariate regression analysis showed that age and presence of hypertension were not risk factors for $\mathrm{OAB}(\mathrm{p}=0.427$ and $\mathrm{p}=0.538$, respectively). In contrast, higher BMI and longer waist circumference were significantly associated with $O A B$ increment risk (1.228-fold; $p=0.001$ and 1.058 -fold; $p=0.001$, respectively). Additionally, multivariate regression analysis found that higher LDL and FG levels were predictive factors for $\mathrm{OAB}$ (1.115-fold; $\mathrm{p}=0.003$ and 1.229 -fold; $\mathrm{p}=0.001$, respectively) (Table 3).

\begin{tabular}{|c|c|c|c|}
\hline & Odds ratio & 95\% Confidence interval & P-Value \\
\hline Age (years) & 1.021 & $0.970-1.075$ & 0.427 \\
\hline BMI (kg/m²) & 1.228 & $1.091-1.382$ & 0.001 \\
\hline LDL (mg/mL) & 1.115 & $0.986-1.044$ & 0.003 \\
\hline FG (mg/dL) & 1.229 & $1.154-1.310$ & 0.001 \\
\hline Waist circumference (cm) & 1.058 & $1.025-1.091$ & 0.001 \\
\hline Hypertension & 1.337 & $0.530-3.373$ & 0.538 \\
\hline
\end{tabular}

TABLE 3: Risk factors for overactive bladder risk according to multivariate regression analysis.

BMI: body mass index; LDL: low-density lipoprotein; FG: fasting glucose

\section{Discussion}

The number of people diagnosed with MS has increased rapidly all over the world in the last few decades. In addition, studies show that MS affects not only the cardiac system but is also related with many diseases, including asthma, cancer, kidney stone, and polycystic ovarian syndrome [10]. In the present study, we 
focused on the relationship between MS parameters and OAB. We found that longer waist circumference, higher BMI, and higher LDL and FG levels were significantly associated with OAB.

Abnormal glucose metabolism is associated with pathological changes in the bladder, including deterioration in muscle contractility, increased oxidative stress, polyneuropathy, inflammation, and irregularity in urothelial sensitivity [11]. Liu et al. investigated the association between type 2 diabetes mellitus and $\mathrm{OAB}$, and reported that the duration of diabetes mellitus was a predictive factor for $\mathrm{OAB}$, but not HbA1c. Additionally, the authors did not include FG in the study [12]. In another study, Yuksel et al. did not find a significant correlation between FG and $\mathrm{OAB}$, but FG was in the normal range for patients with and without $\mathrm{OAB}$ [13]. In the present study, we observed significantly higher FG in participants with OAB. We explain this using the normal glucose levels in the participants with OAB $(99.6 \mathrm{mg} / \mathrm{dL})$; however, mean FG was $111.7 \mathrm{mg} / \mathrm{dL}$ in participants with $\mathrm{OAB}$, which is considered as pre-diabetes.

Pelvic ischemia caused by atherosclerosis is one of the most accepted hypotheses for OAB development. Azadzoi et al. showed that bladder ischemia is associated with reductions in cellular energy production, deterioration in protein synthesis, and increment in cellular immune cellular events, which play a role in OAB development [14]. In addition, the association between atherosclerosis and high LDL level has been proven. Kilinc et al. investigated the role of $\mathrm{LDL}$ in OAB development in the geriatric population, and reported significantly higher LDL levels in patients with OAB using univariate analysis. However, they did not use multivariate regression analysis [15]. In another study, Yuksel et al. stated that LDL level $\geqslant 100 \mathrm{~m} / \mathrm{dL}$ increased OAB risk by 2.8 -fold in post-menopausal women [13]. Similarly, we determined that LDL was a predictive factor for $\mathrm{OAB}$ syndrome in the present study.

Previous reports investigating the relationship between BMI and OAB reported controversial results. Palma and colleagues interviewed 1,045 women to define correlations between BMI and $\mathrm{OAB}$, and claimed that obese women had significantly higher OAB symptoms than those with normal BMI [16]. In another study, AlShaiji and Radomski evaluated the effect of obesity on $\mathrm{OAB}$ and urodynamic parameters [17]. In contrast to Palma et al., Al-Shaiji and Radomski found a significant correlation between higher BMI and urinary leakage, but not OAB. Our study suggested that higher BMI was a risk factor for OAB.

Recent studies have emphasized the importance of obesity type and fat distribution as much as obesity; however, studies investigating the effect of waist circumference on $O A B$ are limited and inconsistent. Central obesity is associated with increased pressure on the bladder, and fat tissue acts like a neuroendocrine organ that produces inflammatory factors and induces the sympathetic nervous system [18]. Lai et al. claimed that longer waist circumference was associated with significantly higher prevalence of urge and mixed urinary incontinence in both sexes, as well as higher prevalence of stress urinary incontinence in women [19]. In another study, Elbaset et al. found a significant relationship between waist circumference and $\mathrm{OAB}$ on univariate analysis, but multivariate regression analysis found that waist circumference was poorly correlated with OAB risk [20]. In the present study, we found significantly longer waist circumference in participants with $\mathrm{OAB}$.

The present study has some limitations. First, the relatively small participant number is considered a limitation of the study. Second, because the study was cross-sectional in nature, we did not evaluate the period required for $\mathrm{OAB}$ development and the influence of relevant parameters. We believe that the interval period between the beginning of OAB and MS could be a subject for another study. Third, the study was conducted in a single academic center. Additionally, we did not investigate the effect of MS on response to treatment for $\mathrm{OAB}$. We believe that the influence of MS on the success of $\mathrm{OAB}$ treatment may be a topic for another study.

\section{Conclusions}

The present study found that higher BMI and longer waist circumference were predictive factors for $\mathrm{OAB}$ in women. Moreover, higher LDL and FG levels increased the risk of OAB development by 1.115- and 1.229fold, respectively. Our study suggests that women with MS should be examined for OAB to improve their quality of life and prevent OAB-related complications. Our study findings must be supported by further studies with prospective design and larger patient volume.

\section{Additional Information \\ Disclosures}

Human subjects: Consent was obtained or waived by all participants in this study. Haseki Training and Research Hospital issued approval 2021 - 0011. Animal subjects: All authors have confirmed that this study did not involve animal subjects or tissue. Conflicts of interest: In compliance with the ICMJE uniform disclosure form, all authors declare the following: Payment/services info: All authors have declared that no financial support was received from any organization for the submitted work. Financial relationships: All authors have declared that they have no financial relationships at present or within the previous three years with any organizations that might have an interest in the submitted work. Other relationships: All authors have declared that there are no other relationships or activities that could appear to have influenced the 


\section{References}

1. Azuri J, Kafri R, Ziv-Baran T, Stav K: Outcomes of different protocols of pelvic floor physical therapy and anti-cholinergics in women with wet over-active bladder: a 4-year follow-up. Neurourol Urodyn. 2017, 36:755-8. 10.1002/nau.23016

2. Teloken C, Caraver F, Weber FA, Teloken PE, Moraes JF, Sogari PR, Graziottin TM: Overactive bladder: prevalence and implications in Brazil. Eur Urol. 2006, 49:1087-92. 10.1016/j.eururo.2006.01.026

3. Milsom I, Abrams P, Cardozo L, Roberts RG, Thüroff J, Wein AJ: How widespread are the symptoms of an overactive bladder and how are they managed? A population-based prevalence study. BJU Int. 2001, 87:7606. 10.1046/j.1464-410x.2001.02228.x

4. Peyronnet B, Mironska E, Chapple C, et al.: A comprehensive review of overactive bladder pathophysiology: on the way to tailored treatment. Eur Urol. 2019, 75:988-1000. 10.1016/j.eururo.2019.02.038

5. Yamaguchi C, Sakakibara R, Uchiyama T, et al.: Overactive bladder in diabetes: a peripheral or central mechanism?. Neurourol Urodyn. 2007, 26:807-13. 10.1002/nau.20404

6. Zacche MM, Giarenis I, Thiagamoorthy G, Robinson D, Cardozo L: Is there an association between aspects of the metabolic syndrome and overactive bladder? A prospective cohort study in women with lower urinary tract symptoms. Eur J Obstet Gynecol Reprod Biol. 2017, 217:1-5. 10.1016/j.ejogrb.2017.08.002

7. Eckel RH, Grundy SM, Zimmet PZ: The metabolic syndrome. Lancet. 20051622, 365:1415-28. 10.1016/S0140-6736(05)66378-7

8. Aguilar M, Bhuket T, Torres S, Liu B, Wong RJ: Prevalence of the metabolic syndrome in the United States, 2003-2012. JAMA. 2015, 313:1973-4. 10.1001/jama.2015.4260

9. Sigit FS, Tahapary DL, Trompet S, Sartono E, Willems van Dijk K, Rosendaal FR, de Mutsert R: The prevalence of metabolic syndrome and its association with body fat distribution in middle-aged individuals from Indonesia and the Netherlands: a cross-sectional analysis of two population-based studies. Diabetol Metab Syndr. 2020, 12:2. 10.1186/s13098-019-0503-1

10. Fu T, Wen T, Yeh P, Chang H: Costs of metabolic syndrome-related diseases induced by obesity in Taiwan . Obes Rev. 2008, 9 Suppl 1:68-73. 10.1111/j.1467-789X.2007.00441.x

11. Lee WC, Chien CT, Yu HJ, Lee SW: Bladder dysfunction in rats with metabolic syndrome induced by longterm fructose feeding. J Urol. 2008, 179:2470-6. 10.1016/j.juro.2008.01.086

12. Liu M, Pan C, Jin M: A Chinese diabetes risk score for screening of undiagnosed diabetes and abnormal glucose tolerance. Diabetes Technol Ther. 2011, 13:501-7. 10.1089/dia.2010.0106

13. Yuksel B, Özgör F, Şahan M, Ozturk S, Can MM, Sarilar O: Correlation between overactive bladder syndrome and severity of coronary artery disease in postmenopausal women. J Coll Physicians Surg Pak. 2020, 30:6226. 10.29271/jcpsp.2020.06.622

14. Azadzoi KM, Yalla SV, Siroky MB: Oxidative stress and neurodegeneration in the ischemic overactive bladder. J Urol. 2007, 178:710-5. 10.1016/j.juro.2007.03.096

15. Kilinc MF, Yasar E, Aydin HI, Yildiz Y, Doluoglu OG: Association between coronary artery disease severity and overactive bladder in geriatric patients. World J Urol. 2018, 36:35-40. 10.1007/s00345-017-2098-1

16. Palma T, Raimondi M, Souto S, Fozzatti C, Palma P, Riccetto C: Correlation between body mass index and overactive bladder symptoms in pre-menopausal women. Rev Assoc Med Bras (1992). 2014, 60:111-7. 10.1590/1806-9282.60.02.007

17. Al-Shaiji TF, Radomski SB: Relationship between body mass index and overactive bladder in women and correlations with urodynamic evaluation. Int Neurourol J. 2012, 16:126-31. 10.5213/inj.2012.16.3.126

18. Ahima RS: Adipose tissue as an endocrine organ. Obesity (Silver Spring). 2006, 14 Suppl 5:242S-9. 10.1038/oby.2006.317

19. Lai H, Gardner V, Vetter J, Andriole GL: Correlation between psychological stress levels and the severity of overactive bladder symptoms. BMC Urol. 2015, 15:14. 10.1186/s12894-015-0009-6

20. Elbaset MA, Taha DE, Sharaf DE, Ashour R, El-Hefnawy AS: Obesity and overactive bladder: is it a matter of body weight, fat distribution or function? A preliminary results. Urology. 2020, 143:91-6. 10.1016/j.urology.2020.04.115 